\title{
Discussion on the Application of Internet of Things in the Development of Smart City
}

\author{
Chunxiu Xu ${ }^{1}$, Shufang Zhao ${ }^{2}$, Xiaoyan Wang ${ }^{3}$, Qian Zhao ${ }^{4}$ \\ 1,2,3,4 Shandong Xiehe University, Jinan, Shandong, 250100, China \\ ${ }^{1}$ Shandong Labor Vocational and Technical College, Jinan, Shandong, 250100, China
}

Keywords: Internet of Things; Smart city; application; construction mode

\begin{abstract}
With the continuous development and progress of computer technology, the integration mechanism of the Internet of things and smart city has become the fundamental choice for conforming to the development of times. In order to improve the comprehensive level of urban construction fundamentally, it is necessary to construct intensive, low-carbon and ecological management path, and to implement the Smart City Pilot Demonstration Project rationally.
\end{abstract}

\section{Overview of Internet of Things Technology}

In recent years, the development of the Internet of things technology develops rapidly, and how to effectively establish corresponding technical management system has become the focus from all walks of life. Especially in the process of setting up and maintaining the smart city, sensor network technology becomes the focus in the industry management system. Moreover, the development of semiconductor technology, microcomputer technology and mobile communication technology has promoted the harmonious development of sensor network technology.

\subsection{Technical Features of the Internet of Things}

In the process of practical application of Internet of things technology, the reasonable data analysis and control system can be established with the aid of computer technology and network information resources, which can provide guarantee for the promotion of the urban construction project, and ensure to implement the information interaction management as well as the upgrade of the technical management system.

Firstly, the technology chain of Internet of things is much more longer, and in the perspective of constituents of the technical system, its technical structure covers the semiconductor technology projects, software communication technology and computer network technology module, etc. Its coverage of the overall technology is wide. Therefore, in the technical management process, the management procedure and control point require to be integrated, and the operation management structure of the energy technology must be optimized reasonably, so that the technology can be play a role in the urban construction.

Secondly, the field of application of the Internet of things technology is wide. In the construction of smart city, the optimization of main economic industries, like industry, agriculture, electric power, etc., needs the aid of the Internet of things technology. At the time of improving the management level and control effect, it not only need to ensure the effective promotion on the economic development, but also to provide the guarantee for the comprehensive construction of the subsequent emerging industrial structure management projects. What's more, it can enhance the level of strategic management effectively and promote the overall progress of the development of smart city.

\subsection{Advantages of the Internet of Things Technology}

Due to the Internet of things technology's own operation characteristics, the technical structure is more flexible and professional in a certain degree. In the actual application system, it really can establish professional management process, the delicate management guidelines, new management 
mode and specialized management path, and can lay a foundation for the optimization pf the overall development efficiency of smart city. For example, the Internet of things technology in the mobile Internet has played an important role. While improving people's living standard, it also provides a good guarantee for the construction of smart city, and creates a certain development atmosphere, which can effectively improve the people's independent cognitive levels. Most of all, in the application of the Internet of things technology, it provides more direct services, and the targeted and precisely effective corresponding services are more effective, which provides the guarantee for application management and construction of smart city.

What's more, only the fragmented services of the Internet of things cannot effectively improve the level of development of smart city, but the integration of Internet of things technology and industry, then build a more macro promotion plan, to ensure that the corresponding management mechanism and control measures can conform to the trend of the development of times, which can provide guarantees for the construction of subsequent systematic platform and commercial platform, and to some extent, can improve the management process. Based on this, the development of smart city from the macro level is to conform to the trend of operation balance of Internet of things technology. In order to give full play of the advantage and value of the Internet of things technology, it must be from the particular scenario and the specific environment, and from the perspective of the actual urban development demand, the more open and flexible management path and management system must be constructed reasonably based on the data parameter of the perception in the physical world.

\section{The Application of Internet of Things in the Development of Smart City}

\subsection{The application in the research and development of urban construction mode}

It must combine the running status of the awareness network equipment of the aware level when applying the Internet of the things technology to the management and development of smart city, and establish the management projects with the real-time access and high-level alignment, ensure the integrity of the control mechanism and management system, and carry out the data classification and processing work rationally, as well as ensure the converting ability of data project into valuable information, so that the basic effective platform can be established. In other words, the application of Internet of things technology in the construction of smart city model can ensure the formation of bottom-up driving city system.

In the establishment of smart city model framework, the urban planning departments have to carry out the top planning management combined with the Internet of the things technology. It must complete the management structure with the application platform and the multiple subsystems. It also needs to ensure the integrity of urban management work and the entire program. Meanwhile, it can apply the internet technology and the corresponding software platform based on the establishment of basic technological platform, so as to ensure the harmonious and unified urban frame structure. For example, in the construction of smart city, the application of android, apple or Windows system can effectively complete the joint of the development projects and application projects. At the time of improving the promoting level, it also provides the assurance for the production of smart city and management services, and ensure that the schema management structure can meet the needs of relevant urban development.

It is worthwhile to say that, people's perception to the physical world is dynamic, and the surrounding environment and technical structure are changing, which requires technical management to carry on the scientific design and management. Based on the present situation of urban development. On the basis of the construction of infrastructure, it must ensure to comply with the structure of urban development, and truly gives the full play to the projects advantages of Internet of things technology. Also, on the basis of meeting the demands of the development suggestion, a foundation for the comprehensive upgrade of follow-up management must be laid. Most importantly, after the establishment of the smart city model, the Internet of things technology should be regarded as the key technology structure of the operation platform, and the research, development and 
management must be carried out based on this.

\subsection{The application in the establishment of smart city business model}

Under the social background of the continuous development of market economy, the trend of times must be complied in order to enhance the level of urban construction rationally. The construction technology systems and operations management must be perfected rationally as well, so that the business model can comply with the market operation requirement. In other words, during the construction of smart city, the construction task and capital management structure should be integrated and controlled, so as to ensure that social capital can participate in the project management system rationally. The most important design link is to establish the corresponding social participatory management and sustainable management, and create a win-win business model.

The effective construction and development of smart city not only relies on the governmental investment projects, but also needs to complete the governmental project installation. After the establishment of the relevant department platform, the investment construction mode in the form of bidding management should be carried out. The nationwide construction of the smart city can be improved in this way. It not only improve the basic construction level, but also create the more efficient urban development space. In recent years, the application frequency of this way is increasing. The smart city is not the independent project of government, but the ground project conforming to the plan. therefore, it is critical to improve the public participation and sensitivity. The openness and social common management level should be optimized, and the sustainable business development mode of the smart city construction can be formed. To play the advantages of the Internet of things technology, maintain the fundamental value of the management level and the social supervision management mechanism effectively, so as to realize the sustainable development of smart city. On the basis of establishing the goal of integrated management, the commercialization model management project of smart city is effectively implemented, which promotes the management level and development effect. In addition, in the construction of smart cities, the systematic supervision mechanism must be implemented actively, and the fusion of corresponding information content must be guaranteed, and the management process and the control effect of more relevant urban development planning must be ensured. In the information network system, the public must be ensured to have the access to relevant valuable information and data.

Firstly, if we want to establish the relevant management path conforming to the development trend of the era, we must attach importance to network information infrastructure construction projects, and complete the public information management level rationally, and need to lay a foundation to the comprehensive optimization and upgrade of the information control effects, as well as integrate the convenience and control effect. That is to say, in the construction of smart city, the Internet of things technology optimized information interaction and sharing level must be used, and the information management platform should be established. The optimization of the development structure must be promoted, and the processing results of the valued information must be enhanced. At present, Telecom operators construct the corresponding basic network system with the aid of Internet of things technology, and the government constructs the city planning of wireless city and optical network, so as to ensure that the construction of infrastructure can really play its value.

Secondly, Radio and Television Networks have been carried out corresponding internet of things projects, and ensure that each project technology can play its real value based on the effective integration of smart city development plan, which promotes the overall progress of the Internet of things technology development structure.

Thirdly, as the city has gradually entered the era of information development, people's life cannot leave the efficient and convenient information management mechanism. In order to effectively implement the low-cost management project, the information structure must be improved. Based on this, the reasonable management and control of the Internet of things technology can not only meet people's basic information needs, but also lay a foundation for the subsequent management process upgrading and conform to the development trend of the era of information consumption. For example, in the construction projects of smart city, the development and implementation of "smart bus" project 
has become the basic development structure, which mainly refers to set the corresponding physical devices on the bus station and buses, to complete the network structure and information collection mechanism on buses effectively, so as to ensure the rationality and real-time vehicle dynamics, providing convenient services for passengers, and create the good spaces for people's traveling. And this improves the service level and the overall effect of infrastructure projects in the smart city, and lays a foundation for the urban sustainable development. In addition, the Internet of things technology is applied to people's daily life as well. Due to the aid of the technical upgrade from every links and elements, the development projects of smart city has become the inevitable trend of the urban planning development. On the basis of the guarantee of running effect on information management market, it also can ensure the introduction of various kinds of social capital in business model, and promote the informatization management more effective.

Fourthly, the operation of the information provider service project, on the basis of building professional service system, fine management and the new control structure, also can guarantee that the government and individuals can obtain corresponding services in the Internet of things technology, and the control and management effect is more in line with the urban development planning and managing project requirements, and can create good information service environment for the full implementation of subsequent business model. It also can realize the goal of sustainable development, and provide the guarantee for the optimization and upgrading of city construction system.

\subsection{The application in the sustainable development model of smart cities}

In the management of smart city, in order to enhance the management level, it needs to adhere to the requirements of sustainable development, and to ensure that the Internet of things technology can be used as strategic emerging industries to play to its real value. It should complete the coordinated management effect between the government and the enterprise rationally, and the management level of structural system of the special funds, which guarantees the research and development and upgrade of Internet of things technology. It needs to be noted that in the operation system of internet of things technology, developers have effectively integrated the product technology scheme and improved the promotion effect with the help of corresponding basic platforms.

Based on this, if we want to promote the urban sustainable development, we need to make full use of the Internet of things technology and combine with the mobile internet. We also need to ensure that the application development projects can be more conformed to urban development. The corresponding We-media platform and basic application services should be centralized and integrated. At the time of forming the fundamental industrial structure system, the comprehensive update of the the Internet of things technology and management projects of smart city should be ensured. And the rational optimization of industry management effect and level of management and control can be promoted. Cities should participate in the basic process of Internet of things technology actively.

Combined with the regulation of industry development, the level of infrastructure and the, construction of foundation platform should be enhanced effectively, providing the basic physical environment for the operation of internet of things technology. At the time of integrating technical system rationally and upgrade the management effect, the comprehensive progress of projects in the cities can be promoted.

\subsection{The application in the collaborative development system}

In the construction of smart city, in order to play the advantages of the Internet of things technology, the project process of the urban renovation should be improved rationally. Make sure to protect public safety and management level of urbanization, the construction of digital medical projects, intelligent transportation projects, and the smart city projects can be implemented.

Therefore, some first-tier cities begin to operate the smart business unit system in smart city management projects, so as to ensure that all modules could give full play to their actual development advantages. 1) digital logistics module; it mainly carries out the Internet of things management on 
warehouse management project and fleet management system, and establishes the command transportation management system, as well as promotes the overall progress of urban basic level of business development.

Intelligent retail mechanism; the shopping, dining and other business can be jointly managed through the Internet of things technology. It sets up the integrated management system, and provides people with a more comprehensive life services. 3) intelligent building projects; The smart buildings are also the key and important points in the application of Internet of things technology, which can ensure the effective implementation and management of urban image monitoring and building energy management projects. 4) intelligent medical projects; the digital integration operation management, intelligence as well as the high-quality nursing program and intelligent clinic projects can be improved. The advantages of the Internet of things technology can be taken, so as to promote the development of smart city.

\section{Conclusion}

To sum up, in the construction of smart city construction, the systematic management mechanism should be implemented actively. At the time of improving the operating structure of the Internet of things technology, the conforming of urban development level to the technical management structure should be ensured, providing citizens with more high-quality and real-time services.

\section{Acknowledgement}

This research was financially supported by 2016 Human and social science project in Shangdong, Project name: "the research on the role of Internet of things in the construction of smart cities in Jinan". (Grant NO. J16WE15).

\section{References}

[1] Chen Liuan, Shi Weinan. Research on the application of the Internet of things and positioning system in the development of smart cities, Science and technology in China, 2016(10):46, 48.

[2] Zhao Lijuan, Zhou Meisha. The Promotion of technological exchanges to lead the industry development -- the 6th China Internet of things industry and smart city development annual conference was successfully held, Intelligent building and smart city,2016(2):30-31.

[3] Yang Huafeng. Research on Shenzhou digital smart city development strategy, Hebei University of technology, 2013.

[4] Zhu Hongbo, Yang Longxiang. Smart city development in the "Internet plus" era and industrial innovation in the Internet of things, Information and communication technology, 2015(5):4-5.

[5] Wang Yanping. Yanhua technology: Internet + Internet of things lead the development of smart cities, Automation Expo, 2015(7):42-43. 